\title{
COMPARATIVE ANALYSIS ON RESPONSES OF VEGETATION PRODUCTIVITY RELATIVE TO DIFFERENT DROUGHT MONITOR PATTERNS IN KARST REGIONS OF SOUTHWESTERN CHINA
}

\author{
ZHOU, Y. ${ }^{1}-$ ZHANG, R. ${ }^{1,2}-$ WANG, S. X. $.^{*}-$ WANG, F. T. ${ }^{1 *}-$ QI, Y. ${ }^{3}$ \\ ${ }^{1}$ Institute of Remote Sensing and Digital Earth, Chinese Academy of Sciences \\ Beijing 100101, China \\ ${ }^{2}$ University of Chinese Academy of Sciences, Beijing 100049, China \\ ${ }^{3}$ Gansu Key Laboratory of Arid Climatic Change and Reducing Disaster, Key Laboratory of \\ Arid Climatic Change and Disaster Reduction of CMA, Institute of Arid Meteorology \\ China Meteorological Administration, Lanzhou 730020, China \\ *Corresponding authors \\ e-mail:wangsx@radi.ac.cn,wangft@radi.ac.cn \\ (Received $19^{\text {th }}$ Sep 2018; accepted 22 ${ }^{\text {nd }}$ Nov 2018)
}

\begin{abstract}
The climate conditions are complex and diverse in Southwest China (SWC), especially the karst area, and the interaction between climate change and terrestrial ecosystems has become complex. Vegetation productivity is an important indicator in terrestrial ecosystems, and can visually reveal the impacts of extreme climate. Drought affects not only the process of photosynthesis directly, but also the changes in vegetation productivity from other forms of interference with photosynthesis. Against this background, we analyzed the time series and spatial distribution characteristics of drought, the temporal and spatial distribution and anomalies of vegetation productivity. For the observation period 2001-2012, we used different drought monitor patterns (including Pa, SPI, SPEI and PDSI) to assess the impact of drought on vegetation productivity (annual NPP and monthly GPP). We mainly want to explore the response of different monitor patterns to vegetation productivity at different stages. NPP exhibited considerable variation during 2001-2012; the droughts in 2009 and 2010 led to NPP reduction by $14.7 \%$ and $8.4 \%$, respectively. The NPP is directly proportional to the severity of drought, severe drought had a greater impact on monthly GPP than mild drought, especially for evergreen forests, shrublands, and deciduous forests, while little variation was found for croplands. We compared drought indicesvegetation productivity during the drought season between 2009 and 2010; SPEI has a better correlation with SPI and PDSI. The results demonstrate that SPEI and PDSI are most capable of monitoring the vegetation drought conditions. There will be large differences of the influence on vegetation productivity on different drought levels. Our findings suggested that multi-indices in drought monitoring are needed in order to acquire robust conclusions.
\end{abstract}

Keywords: remote sensing, sustainability, patterns, MODIS product, karst mountain area

\section{Introduction}

The Intergovernmental Panel on Climate Change (IPCC) concluded that the climate has changed over the past century and the frequency and intensity of extreme climate events have become more frequent in recent years (Judi et al., 2018). Increase in the frequency and intensity of extreme climatic events (especially meteorological disasters) could have significant impact on vegetation ecosystems (Chen et al., 2012), resulting in lower crop yields, increased loss of forest biomass, higher disease and insect damage (Dai, 2011). Drought is a critical phenomenon of climatic change, and formation 
mechanism is more complicated than floods (Dewes et al., 2017). Drought impacts ecosystem mortality, net primary productivity (NPP), gross primary productivity (GPP), and carbon storage worldwide (Zhang et al., 2012; Zhao, 2010). Vegetation productivity is an essential flux in the net ecosystem exchange of $\mathrm{CO}_{2}$ between the atmosphere and terrestrial ecosystems. It is a key component of the carbon cycle (Piao et al., 2006) and an important indicator for ecosystems. Regional estimates of vegetation productivity are useful for modeling the regional and global carbon cycles. Quantitative estimates of NPP and GPP at a regional level are significant on the global scale for understanding changes in ecosystem structure and function, and predicting terrestrial carbon cycle trends, which determines the sustainable use of natural resources and helps make policy decisions. Previous studies have shown that (Huang et al., 2016) nearly half of the large-scale ecosystem carbon cycle anomalies are caused by drought. With climate change drought events will increase, therefore it is now urgent that we gain a better understanding of the impact of drought on regional carbon ecosystems in forest ecosystems.

Drought indices are a standard for characterizing drought and have been used widely to detect drought intensity, duration, and spatial distribution. Meteorological factors as well as hydrological, soil, crop, irrigation should be considered when monitoring drought, drought characteristics and impacts are very complex. Various drought indices have been developed recently, including the percentage of precipitation anomaly (Pa) (Foley, 1957), the Palmer drought severity index (PDSI) (Palmer, 1965), drought area index (DAI) (Dai et al., 1965), standardized precipitation index (SPI) (McKee et al., 1995), and the standardized precipitation evapotranspiration index (SPEI) (Vicente, 2009). Many scholars use different drought indices to simulate drought and draw a series of results. He et al. (2016) analyzed wheat potential productivity and drought severity during 1962-2010 based on a wheat drought severity index. Wang et al. (2014) used meteorological data from 128 meteorological stations during 1960-2012 based on a standardized precipitation evapotranspiration index to analyze annual variation trends in drought and drought intensity, the frequency of drought events, and the relationship between drought and ENSO events. Wang et al. (2012) used a relative moisture index to analyze the spatial distribution and annual variation in drought frequency and intensity.

Drought monitor patterns of indices have characteristics. Precipitation was considered in Pa and SPI, with simple calculation and flexible time scale. PDSI was a good indicator of soil moisture fluctuations, in which monthly surface temperature was added as input. And precipitation and evapotranspiration were considered in SPEI. These three patterns for monitoring drought are widely used recently.

The resistances of vegetation productivity to drought could estimate the stability of an ecosystem. Understanding the responses of vegetation productivity to drought is very important. Some previous literatures are mainly focused on the effect of meteorological element or single drought monitor patterns on vegetation productivity. Graw et al. (2017) analyzed vegetation productivity and compared precipitation-vegetation dynamics during the drought season in Eastern Cape. Ghali and Nejla (2017) analyze changes of the vegetation productivity and responses to the ongoing drought based on NDVI time series. Zhang et al. (2014) showed the impact of drought on vegetation productivity using PDSI index in the Lower Mekong Basin. Skagen (2018) and Chang et al. (2018) highlighted more significant responses of precipitation and forest structure to drought over a long time scale. 
Consequently, the impact of different drought monitor patterns on the vegetation productivity is not completely understood, especially in some local places of karst regions of Southwestern China. In the karst area, evaporation and infiltration of water are particularly serious. Hence, it is necessary to analyze the relationship between drought and vegetation productivity in karst ecosystems.

This work aims to analyze response of vegetation productivity in different patterns of drought indicators in karst regions in order to reveal the process and extent of drought disasters, and understand the impacts of extreme weather events. Despite an existing of literature which has quantified the characteristics of drought change, analyzed the spatial distribution of drought intensity and frequency, and determined its impact on terrestrial vegetation productivity, the influence on vegetation productivity under different patterns of drought indicators has not yet been explicitly addressed. Considering an increasing number of drought events, the analysis of vegetation response to drought events, provides valuable spatial information related to interannual variability. The changes in vegetation productivity are needed for further identification of climate change on carbon budget of regional ecosystem. This will contribute to the explanation of the impact of drought disaster on subtropical and karst mountain ecosystem in SWC.

The objectives of this work were: (i) to characterize and classify drought hazard occurrence based on different patterns of drought indicators during the last 10 years; (ii) to monitor vegetation productivity and analyze NPP anomalies; (iii) to analyze the impact of drought on monthly GPP and compare drought sensitivity with drought index in different drought monitor patterns, and particular different stages of drought occurrence. Vegetation productivity assessment between vegetation condition and detailed analysis on drought impact within different vegetation system were conducted.

\section{Materials and Methods}

\section{Study Area}

The study area is located at $97^{\circ} 35^{\prime} \sim 112^{\circ} 06^{\prime} \mathrm{E}, 20^{\circ} 90^{\prime} \sim 35^{\circ} 31^{\prime} \mathrm{N}$, and includes Yunnan, Sichuan, Guizhou, and Guangxi Provinces, and Chongqing City. The "four provinces and one city" cover an area of $113.76 \times 104 \mathrm{~km}^{2}$, which accounts for $11.77 \%$ of the total area (Fig. 1).

The terrain is complex, and includes the West Sichuan Plateau, the Yunnan-Guizhou Plateau, the Hengduan Mountains, the Sichuan Basin, and the hills of Guangxi. In the region, widespread karst, undulating terrain, barren soil, and the influence of regional climate result in significantly different climate characteristics, in which wide canyons, intensive rivers, and the region's landforms are dominated by plateaus and mountains. The dominant vegetation types include evergreen forest, deciduous forest, mixed forest, shrub, savanna, grassland, cropland and wetland. The region is rich in runoff, rapid water flow, and large droplets, and is the most abundant water resource area in China holding approximately $40 \%$ of the country's water resources.

With locating in low latitudes, it is dominated by subtropical monsoon climate with distinct wet and dry conditions. Mean annual precipitation is $1000-1300 \mathrm{~mm}$, with a dry season (from October to April) and rainy season (from May to September). The average annual temperature is $17^{\circ} \mathrm{C}$. The spatial and temporal distribution of precipitation is extremely uneven. During the study period, SWC experienced three severe droughts; the first was from September 2006 to December 2007, another was from December 
2007 to February 2008, and the most serious was from October 2009 to April 2010, which resulted in a long period of drought over a wide geographic area that had great impact on the country (He et al., 2014). The severe drought event not only significantly affected the daily lives of millions of people but also impacted the terrestrial ecosystem productivity and the carbon cycle in the context of global change.

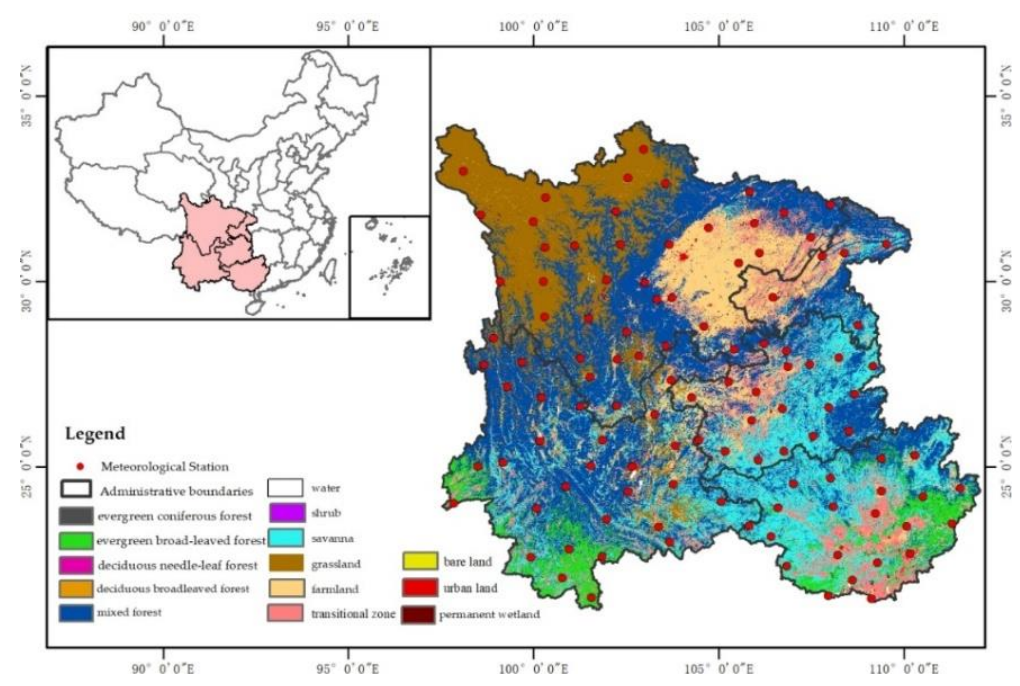

Figure 1. Location of study area and vegetation types. vegetation was obtained from FROMGLC 2010 land cover product

\section{Data and Methods}

In order to illustrate the sensitivity of vegetation productivity under different patterns of drought indicators in karst regions of southwestern China, we analyzed the time series and spatial distribution characteristics of drought in the southwestern region as indicated by three different drought patterns (Tang and Anwaer, 2012). At the same time, data on vegetation productivity was preprocessed using monthly GPP data from MOD17A2H and annual NPP data from MOD17A3H, and used to calculate the monthly GPP and annual NPP, while analyzing the temporal and spatial distribution and anomalies of vegetation productivity. Then, the drought response of different vegetation types to vegetation productivity was considered. Finally, the response of different patterns of drought indicators was obtained.

\section{Meteorological data}

To illustrate different drought patterns, the meteorological datasets employed in this study were derived from 112 meteorological observation stations (Fig. 1) in SWC (Chongqing, Sichuan, Guizhou, Yunnan, and Guangxi) over the period 1980 to 2012. Data collected from the National Meteorological Information Center of China Meteorological Administration, included average daily temperature, precipitation, wind speed, sunshine hours, solar radiation, and water vapor pressure among others. The reliability and homogeneity of the monthly meteorological data were controlled and checked by the Chinese Meteorological Administration before its release (Yu et al., 2014). We chose daily mean temperature, daily total precipitation, and water vapor 
pressure for this paper, the records were then interpolated to a grid at a resolution of 0.5 $\times 0.5^{\circ}$ (Hutchinson and $\mathrm{Xu}, 2004$ ) with a smooth thin-plate spline entry method. To fit the calculation of the data with other data, the gridded meteorological datasets were reprojected and resampled to a resolution of $500 \mathrm{M}$.

\section{Drought indicators}

Since the aim of this work is to understand different patterns of drought indicators impacts on vegetation productivity during severe drought events. Drought indices have been used widely to detect drought intensity, duration, and spatial distribution. Drought characteristics and their impacts are very complex. We selected three patterns (includes four indices). Firstly, Pa and SPI indices, which mainly considering the impact of precipitation; secondly, PDSI index, which is an indicator of soil moisture fluctuations, in contrast to Pa and SPI indices that are based solely on precipitation information, PDSI uses both precipitation and temperature as inputs. Thirdly, SPEI index, considering precipitation and evapotranspiration, and retaining the sensitivity of SPI and PDSI to drought events, reflect the intensity, duration of drought and changes in different time scales. These three patterns for monitoring drought are widely used in recent years.

\section{The percentage of precipitation anomaly $(\mathrm{Pa})$}

$\mathrm{Pa}$ is a good indicator of precipitation fluctuation, which is the percentage of the anomaly between the precipitation and the average precipitation in the same period (Yao et al., 2018), reflects the deviation and drought conditions of a period of abnormal precipitation (Li and Yang, 2017). As values above $-0.5,-0.5$ to $-0.7,-0.7$ to $-0.85,-0.85$ to -0.95 , and below -0.95 represent none, mild, moderate, severe, and extreme drought, respectively.

The Pa was calculated as follows:

$$
\mathrm{Pa}=\frac{r-\bar{r}}{\bar{r}}
$$

where: $\mathrm{r}$ is a certain period of precipitation, $\bar{r}$ is the period of the average annual precipitation. Later, Yangand Li (1994) defined the precipitation anomaly percentage as the water anomaly index $\mathrm{Zi}$ for a given time scale. The formula is:

$$
\mathrm{Zi}=\frac{R i-\frac{1}{n} \sum_{j=1}^{n} R i j}{\frac{1}{n} \sum_{j=1}^{n} R i j} \times 100 \%
$$

where: $R i j$ is the amount of precipitation in year $\mathrm{j}$ month $\mathrm{i}, \mathrm{n}$ is the number of samples, $R i$ is the precipitation of month $\mathrm{i}$ during the monitoring months, and $\mathrm{Zi}$ is the percentage of precipitation anomaly in month $i$.

\section{The standardized precipitation index (SPI)}

SPI is an indicator of the probability of precipitation occurring during a period (Carbone et al., 2018). In the case of precipitation analysis and drought monitoring and evaluation, the distribution probability $\Gamma$ is used to describe the change in precipitation. 
SPI is obtained by calculating the probability $\Gamma$ of precipitation distribution in a certain period of time. Then, standardize it to normal. The drought level is then divided by the distribution of the cumulative frequency of standardized precipitation. As values of above $-0.5,-0.5$ to $-1.0,-1.0$ to $-1.5,-1.5$ to -2.0 , and below -2.0 represent none, mild, moderate, severe, and extreme drought, respectively. For each pixel, monthly precipitation can be accumulated into different time scales (e.g., 1, 2, 3, 6, 9, 12, and 24 months). The calculation of SPI is as follows:

$$
\mathrm{SPI}=\mathrm{Sd} \frac{t-\left(C_{2} t+C_{1}\right) t+C_{0}}{\left(\left(d_{3} t+d_{2}\right) t+d_{1}\right) t+1.0}
$$

where: $t=\sqrt{\ln \frac{1}{G(x)^{2}}}, \mathrm{G}(\mathrm{x})$ is the distribution of probability of precipitation associated with the function; $x$ is the precipitation sample value; and $\mathrm{s}$ is a positive or negative coefficient of probability density.

- When $G(x)>0.5, G(x)=1.0-G(x), \mathrm{s}=1$.

- When $G(x) \leq 0.5, G(x)$ is obtained from the distribution function $\Gamma$ probability density integral formula,

$$
\mathrm{G}(\mathrm{x})=\frac{1}{\beta^{\gamma} \Gamma(\alpha)} x^{\gamma-1} e^{\gamma-1} d_{x}, \mathrm{~s}=-1 ; \mathrm{x}>0
$$

where $\gamma$ and $\beta$ are the shape and scale parameters of the distribution function; $C_{0}, C_{1}, C_{2}$ and $d_{1}, d_{2}, d_{3}$ are the conversion functions of the distribution function $\Gamma$ to the cumulative frequency, which simplifies the calculation of the approximate solution formula and takes the following values: $C_{0}=2.515517 ; C_{1}=0.802853 ; C_{2}=$ $0.010328 ; d_{1}=1.43278 ; d_{2}=0.189269 ; d_{3}=0.001308$.

\section{The standardized precipitation evapotranspiration index (SPEI)}

To calculate SPEI (Zhao et al., 2018), the monthly difference between precipitation (P) and potential evapotranspiration (PET) is used, in which the Thornthwaite method is used to calculate the PET, and monthly temperature as inputs. The difference between $\mathrm{P}$ and PET for the month $\mathrm{i}$ is calculated as follows:

$$
D_{i}=P_{i}-P E T_{i}
$$

The $\mathrm{D}$ values are aggregated at various time scales:

$$
\mathrm{D}_{n}^{k}=\sum_{i=0}^{k-1}\left(P_{n-i}-P E T_{n-i}\right), \quad n \geq k
$$

where $\mathrm{P}$ is precipitation, PET is the potential evapotranspiration calculated by Thornthwaite method, $\mathrm{k}$ is the timescale of the aggregation and $\mathrm{n}$ is the calculation number, respectively. $\mathrm{D}_{n}^{k}$ is based on both the $\mathrm{n}^{\text {th }}$ climatic water balance and the water balance for the preceding k-1 months. The criteria for drought classification based on SPEI is referenced as defined in McKee et al. (1993) and Potopová et al. (2015). 


\section{The Palmer Drought Severity Index (PDSI)}

PDSI is a good indicator of soil moisture fluctuation (Huang et al., 2012; Angelidis et al., 2012), which is based on the supply and demand concept of the water balance equation (Mika et al., 2005; Heddinghaus, 1991). PDSI is different from the SPI and SPEI, as its time scale is fixed. The index is calculated using precipitation, temperature, and soil parameters. PDSI is calculated as follows:

$$
X_{i}=0.897 X_{i-1}+Z_{i} / 3
$$

where $X_{i}, X_{i-1}$ are the current PDSI and previous month's PDSI, respectively. $Z_{i}$ is the current water abnormality index, which is determined through precipitation. The $X_{i-1}$ term accounts for the effect of duration of drought, while the value of $\mathrm{Z}$ is given as follows:

$$
\begin{gathered}
Z=d K \\
K=\frac{\overline{E T}+\bar{R}}{\bar{P}+\bar{L}}
\end{gathered}
$$

where $\mathrm{K}$ is the climatic weighing factor, $\overline{E T}$ is the average evapotranspiration, $\bar{R}$ is the average runoff, $\bar{P}$ is the average precipitation, and $\bar{L}$ is the average loss of soil moisture.

Four drought indices can be used to assess the severity degree of droughts, and also we collected $20 \mathrm{~cm}$ soil water value (SMV) from some sites during the study period, the monitoring results for each index were compared with the actual data. The category of drought severity was based on the National Standard of the People's Republic of China's "Classification of meteorological drought" (GB/T 20481-2006) and McKee et al. (1993) is shown in Table 1.

Table 1. The standard Drought severity category based on drought indices

\begin{tabular}{c|c|c|c|c|c}
\hline $\begin{array}{c}\text { Drought } \\
\text { grade }\end{array}$ & Non-drought & $\begin{array}{c}\text { Mild } \\
\text { drought }\end{array}$ & $\begin{array}{c}\text { Moderate } \\
\text { drought }\end{array}$ & $\begin{array}{c}\text { Severe } \\
\text { drought }\end{array}$ & $\begin{array}{c}\text { Extreme } \\
\text { drought }\end{array}$ \\
\hline $\mathrm{Pa}$ & $-0.5<\mathrm{Pa}$ & $-0.7<\mathrm{Pa}<-0.5$ & $-0.85<\mathrm{Pa}<-0.7$ & $-0.95<\mathrm{Pa}<-0.85$ & $\mathrm{~Pa}<-0.95$ \\
$\mathrm{SPI}$ & $-0.5<\mathrm{SPI}$ & $-1.0<\mathrm{SPI}<-0.5$ & $-1.5<\mathrm{SPI}<-1.0$ & $-2.0<\mathrm{SPI}<-1.5$ & $\mathrm{SPI}<-2.0$ \\
$\mathrm{SPEI}$ & $-0.5<\mathrm{SPEI}$ & $-1.0<\mathrm{SPEI}<-0.5$ & $-1.5<\mathrm{SPEI}<-1.0$ & $-2.0<\mathrm{SPEI}<-1.5$ & $\mathrm{SPEI}<-2.0$ \\
$\mathrm{PDSI}$ & $-1.0<\mathrm{PDSI}$ & $-2.0<\mathrm{PDSI}<-1.0$ & $-3.0<\mathrm{PDSI}<-2.0$ & $-4.0<\mathrm{PDSI}<-3.0$ & $\mathrm{PDSI}<-4.0$ \\
$\mathrm{SMV}$ & $0.8<\mathrm{SMV}$ & $0.6<\mathrm{SMV}<0.8$ & $0.5<\mathrm{SMV}<0.6$ & $0.4<\mathrm{SMV}<0.5$ & $\mathrm{SMV}<0.4$ \\
\hline
\end{tabular}

\section{Vegetation productivity datasets}

We adopted annual MOD17A3H NPP products and monthly GPP MOD17A2H GPP products from the Numerical Terradynamic Simulation Group (www.ntsg.umt.edu) over the period 2000-2012. The MOD17H (MOD17A2H and MOD17A3H) product provides a description of the Gross and Net Primary Productivity designed for the MODIS sensor aboard the Aqua and Terra platforms. MOD17A2H Version 6 is a GPP product, a cumulative 8-day composite of values with a 500-meter pixel size based on the 
LAI/FPAR, which is related to assimilation (Propastin et al., 2012; Leinenkugel et al., 2013). GPP is the amount of carbon absorbed by ecosystems through photosynthesis and is an important component in land-atmosphere $\mathrm{CO}_{2}$ exchange. MOD17A3H provides annual NPP at a spatial resolution of $500 \mathrm{~m}$, delivered as a gridded Level-4 product in sinusoidal projection. The terrestrial ecosystem NPP is based on data which references the BIOME-BGC model and the light energy utilization model (Jiao et al., 2014; Neumann et al., 2016; Zhang et al., 2008). The products have been recently improved by temporally filling missing and cloud contaminated FPAR/LAI based on the biome parameter look-up table (BPLUT). BPLUT is based on 2839 recently synthesized NPP data which is from the daily Global Modeling, then Assimilation Office (GMAO) meteorological data and the temporal filling of unreliable FPAR greatly improve the accuracy of inputs. To extract the data by mask, the map projection conversion tools and mosaic tools for data projection transformation in MODIS MRT (MODIS Reprojection Tool). We extracted the effective values using the band math tool in ENVI 5.3.

Zhang et al. (2008) indicates that the MOD17 GPP was underestimated (particularly for the cropland) by using measured GPP from eddy covariance flux. As this work mainly analyzed the change of gross primary productivity under different vegetation, the land cover data would be combined with MOD17 parameters. The MOD17 algorithm significantly improved the accuracy of GPP estimates. Neumann et al. (2016) compared MODIS EURO with terrestrial driven NPP, and found that MODIS EURO product provided a consistent, temporally continuous and spatially explicit productivity dataset and was good for elevation. As a result MOD17 products can be used to assess climate change impacts on ecosystems.

\section{Land cover information}

We used FROM-GLC2010 land cover product (Ran et al., 2009) at a spatial resolution of $500 \mathrm{~m}$ to identify different vegetation types in SWC (http://data.ess.tsinghua.edu.cn). This product was based on multi-source land cover classification, considered accuracy of MOD12Q1 land cover product, and used a common classification system (the International Geosphere-Biosphere Programme (IGBP) land-cover classification system). The accuracy of the FROM-GLC 2010 product was validated through comparison with numerous data, including Google Earth, Landsat TM, MODIS land cover, with an overall accuracy of 75\% (Yu et al., 2013). These data were used to validate the results of global land surface potential wetland mapping. In the map, vegetation was classified into evergreen broad-leaved forest, evergreen coniferous forest, deciduous broad-leaved forest, deciduous coniferous forest, mixed forest, shrub, savanna, grassland, cropland and wetland. Land cover information was adjusted to improve the accuracy of MOD17 GPP, which provides a consistent, temporally continuous and spatially explicit productivity dataset.

\section{Assessing the impacts of drought on vegetation productivity}

The standardized anomaly index (SAI) has been widely employed in the evaluation of precipitation trends (Boczon et al., 2016; Komlan et al., 2017). This index has also been applied effectively to the measurement of NPP anomalies. Here, the NPP simulation value was used to detect monthly NPP anomalies. The effect of drought on the productivity of the vegetation was characterized by the standardized anomaly index (SAI). 


$$
\mathrm{SAI}_{\mathrm{NPP}}(\mathrm{n})=[\mathrm{NPP}(\mathrm{n})-\overline{\mathrm{NPP}}] /\left(\delta_{\mathrm{NPP}}\right)
$$

where, $\operatorname{SAI}_{\mathrm{NPP}}(\mathrm{n})$ represents the NPP anomalies, $\mathrm{n}=1,2,3, \ldots, 12, \mathrm{NPP}(\mathrm{n})$ is the annual NPP, NPP is the value of mean NPP, and $\delta_{\text {NPP }}$ is the standard deviation of the NPP. Abnormal forest productivity is divided into: Normal ( $|\mathrm{SAI}| \leq \mathrm{AIm})$, mildly abnormal $(0.5<|\mathrm{SAI}| \leq \mathrm{A})$, moderately abnormal $(1<|\mathrm{SAI}| \leq \mathrm{AIe})$, severely abnormal $(1.5<$ $|\mathrm{SAI}| \leq \mathrm{A})$, and extreme anomaly $(|\mathrm{SAI}|>2)$. The positive and negative values of SAI represent an increase or decrease in forest productivity, respectively. The larger the absolute value, the more serious the abnormal situation.

To investigate the impact of drought (El-Vilaly et al., 2017) on vegetation productivity (GPP and NPP), we calculated the percentages of drought affected areas $(\mathrm{Pa}<-50 \%$, SPI $<-0.5)$, and then analyzed their correlation with the regional mean NPP among 2001-2012. In order to be consistent with the resolution of NPP and GPP, we resampled $\mathrm{Pa}$, SPI, and meteorological data to $1 \mathrm{~km}$ spatial resolution. Then, we calculated the monthly average GPP for the dominant vegetation types and calculated the relative changes of NPP under different drought levels. The purpose is to analyze the response of different vegetation types to different degrees of drought over the study period. To understand the seasonal characteristics of the effects on the vegetation productivity, we calculated monthly mean GPP and compared it with the meteorological anomalies and effects on productivity for different seasons among 12 years. At the same time, we chose the year of abnormal drought (2009-2010) to measure the NPP reduction of different vegetation types.

\section{Results}

\section{Drought conditions in Southwest China from 2001 to 2012}

We selected daily meteorological data from 1980 to 2012 in SWC, and analyzed the spatial and temporal distribution of drought by calculating drought indicators, Pa, SPI, SPEI and PDSI.

According to drought record, there were three major drought events from 2001 to 2012 (Table 2): June to October 2006; December 2007 to February 2008; and October 2009 to April 2010.

Table 2. Drought events and characteristics from 2001-2012

\begin{tabular}{|c|c|c|}
\hline Drought events & Duration & Mean Precipitation \\
\hline $\begin{array}{l}2006 \text { summer drought } \\
2008 \text { winter drought } \\
2009 \text { drought }\end{array}$ & $\begin{array}{c}\text { June to October 2006, } 5 \text { months } \\
\text { December } 2007 \text { to February 2008, } 3 \text { months } \\
\text { October } 2009 \text { to April } 2010,6 \text { months }\end{array}$ & $\begin{array}{c}1050 \mathrm{~mm} \\
1180 \mathrm{~mm} \\
975 \mathrm{~mm}\end{array}$ \\
\hline
\end{tabular}

In the summer of 2006, most of the eastern part of SWC suffered the most severe droughts since meteorological records began. The drought continued over a particularly long period and had a wide range of impacts, which led to serious economic loss. In the winter of 2008, drought was widespread in most parts of the southwest and severe drought presented in many areas. The area suffered a once-in-a-century drought from winter 2009 to spring 2010, which lasted for nearly eight months. The affected area is $0.8 \times 107 \mathrm{hm}^{2}$, approximately 8 million ha. A large number of crops failed, and 25 
million people had to cope with less water, resulting in huge economic losses. The following is a detailed explanation of the 2009 drought.

The distribution of the drought indices can be seen in Fig. 2. In September and October 2009, the drought began, and drought in eastern Yunnan and central Guizhou was sporadic. From November and December, the drought expanded rapidly, and severe drought occurred in the south of Sichuan, the northwestern Sichuan Basin, and the vast majority of Yunnan. In January and February, the drought was more serious, and heavy drought occurred in the Sichuan Basin, the northwest edge of Yunnan, the southern tropical rainforest fringe, and across Guizhou (excluding the southeastern parts). Drought in most of Chongqing, eastern Sichuan, eastern Guizhou and local areas in Yunnan eased in March, but severe drought occurred in central and eastern Yunnan, south Sichuan, and west Guizhou. The drought came to an end in April. The development of drought reflects the characteristics of "rapid, contiguous, and sequential".
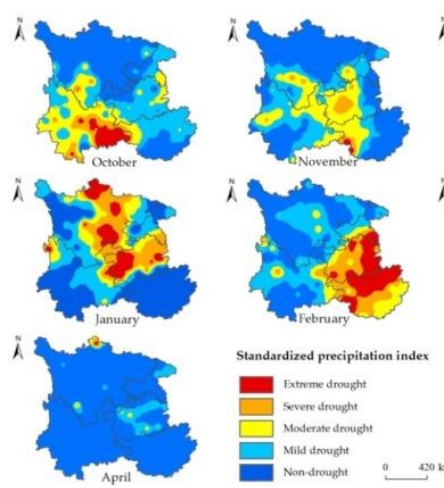

(a)
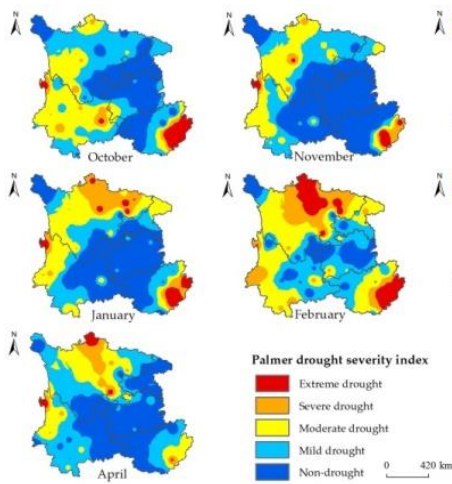

(c)
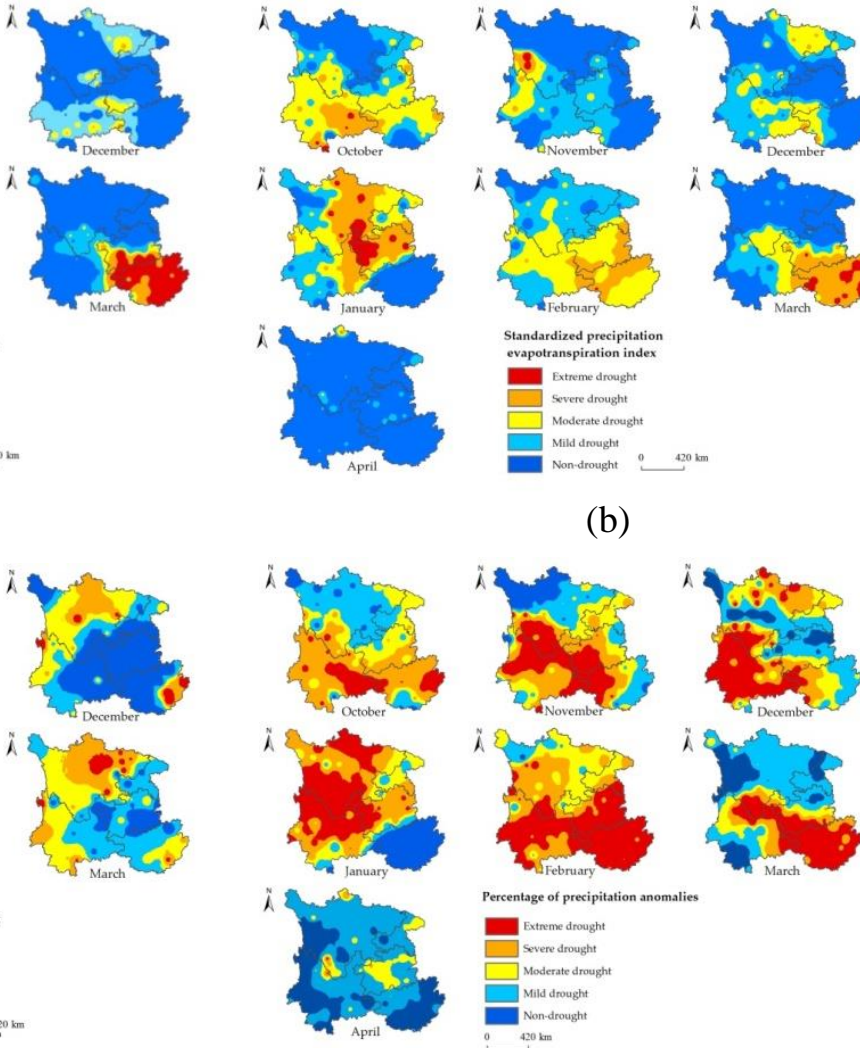

(b)

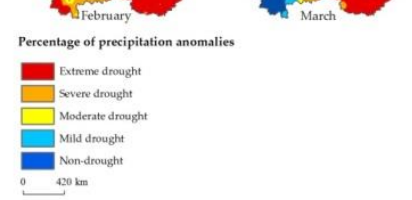

(d)

Figure 2. Spatial distribution of drought indices in SWC from October 2009 to April 2010: (a) $P a$, (b) SPI, (c) SPEI and (d) PDSI

Each drought monitoring indices has different characteristics. Pa is characterized by a large arid range and contiguous time, and mainly for concentrated in Yunnan, Guangxi. Pa is highly correlated with precipitation. SPI is similar to $\mathrm{Pa}$ in spatial distribution and is reduced in scope. The period of drought is mainly concentrated from January to March 2010, the most serious occurred in Guangxi. SPEI characterizes the effect of temperature and surface evapotranspiration, mainly for moderate and severe 
drought while, the scope of extreme drought is small. The drought area had further expanded in January 2010. PDSI is different from the SPI and SPEI, as its time scale is fixed, which is a good indicator of soil moisture fluctuation. The severity and extent of the drought have further expanded from January 2010 to March 2010, especially in the central part of Sichuan Province. From the perspective of the entire drought process, winter is more serious.

Correlation between the $20 \mathrm{~cm}$ soil moisture value (SMV, from National Meteorological Information Center, http://data.cma.cn) and drought indices shows that a significant test of Pearson 0.01 was passed between the drought monitoring indices based on monthly scale and are positively correlated (Table 3). SPEI has the highest correlation with SPI, the correlation coefficient is 0.695; the second is SPI and Pa, and the correlation coefficient is 0.683 . The correlation between the same monitoring mode and the drought monitoring index is higher, which indicates that the need for drought monitoring based on different patterns. There is a good correlation between the drought index and soil moisture value at the monthly time scale. The correlation between SMV and SPEI is the highest, the correlation coefficient is 0.632. This quantitatively illustrates that SPEI has a better monitoring effect among the several drought indices.

Table 3. The correlations between soil moisture and drought indexes

\begin{tabular}{cccccc}
\hline & SMV & Pa & SPI & SPEI & PDSI \\
\hline SMV & 1.000 & & & & \\
Pa & $0.587^{* *}$ & 1.000 & & & \\
SPI & $0.591^{* *}$ & $0.683^{* *}$ & 1.000 & & \\
SPEI & $0.632^{* *}$ & $0.462^{* *}$ & $0.695^{* *}$ & 1.000 & \\
PDSI & $0.616^{* *}$ & $0.637^{* *}$ & 0.455 & $0.508^{* *}$ & 1.000 \\
\hline
\end{tabular}

Note: * represents 0.05 bilateral significance level; ** represents 0.01 bilateral significance level

After analyzing temperature and precipitation data (Fig. 3a), precipitation shortages were observed during 2005-2006 and 2008-2009, while relatively high temperatures were observed for most of 2006 and 2009-2010. In 2009-2010, the annual average temperature was $0.5^{\circ} \mathrm{C}$ higher than those among 12 years. In addition, the total annual rainfall in 2009 is $10 \%$ lower than the average of 12 years. Although the total precipitation in 2010 is close to the long-term average, and the average regional rainfall was only $60 \%$ of the 12-year average from September to December 2009. The relationship between precipitation and drought response to vegetation indicated a lag effect.

Relatively extensive and severe droughts occurred in 2004, 2006 and 2009, which affected all SWC regions. Drought indices show the same trend (Fig. 3b), reached lower values in 2009. In 2006 and 2009, there was less precipitation and high temperatures, which were conducive to the formation of dry weather conditions. The intensity and extent of drought in 2009 were more severe than those in 2006 and 2008, and the total area affected accounted for $95 \%$ of SWC (52\% severe drought and $43 \%$ mild drought), whereas in 2006, the degree of drought was relatively light, accounting for only $58.7 \%$. Furthermore, the most severely affected region was located in Guangxi, with a mean SPEI was -0.4 in March 2009, lower than the average of the 12-year. This is mainly caused by the simultaneous high temperatures and insufficient precipitation. 


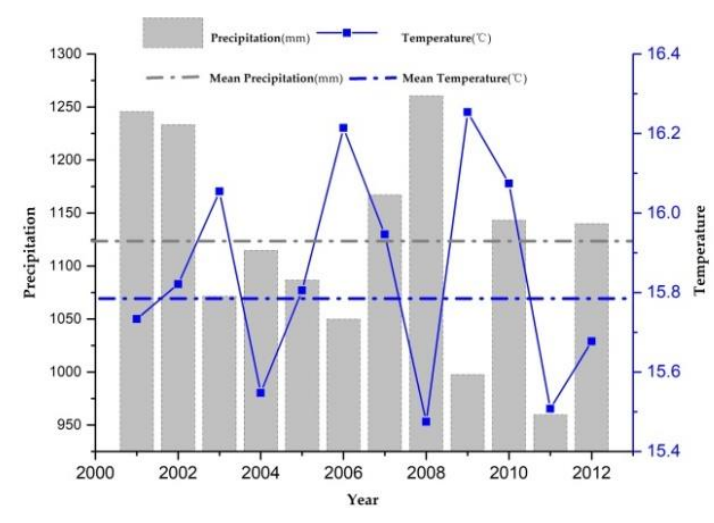

(a)

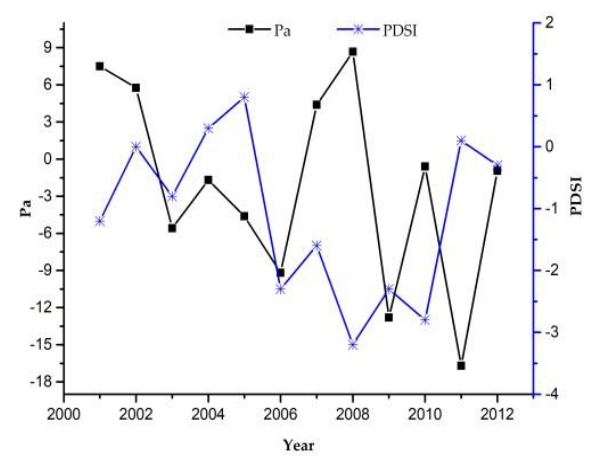

(b)

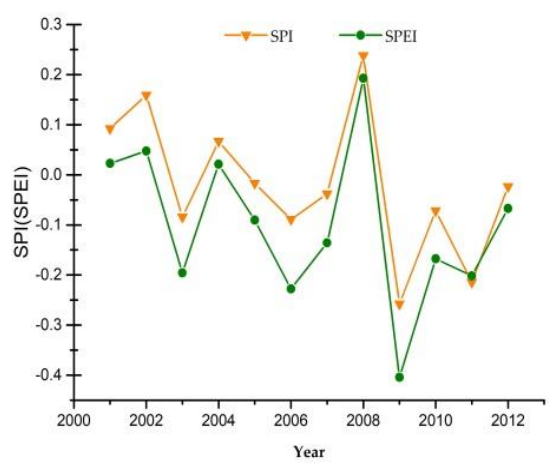

(c)

Figure 3. Annual variations for meteorological data and drought indices from 2001 to 2012:

(a) precipitation and temperature (b) Pa and PDSI indices (c) SPI and SPEI indices

\section{NPP analysis and Drought impacts on annual NPP}

Fig. 4 shows spatial distribution of mean annual NPP from 2001 to 2012, which varied from nearly $142 \mathrm{~g} \mathrm{C} \mathrm{m}^{-2}$ year ${ }^{-1}$ in the western Sichuan region to over $1521 \mathrm{~g} \mathrm{C}^{-}$ $\mathrm{m}^{-2}$ year $^{-1}$ in southern Yunnan. Due to the wide variety of vegetation in SWC and the large regional climate differences, the spatial distribution of NPP is uneven and reduces from southeast to northwest; the average occurs in central and southern Guangxi, while the values are higher in eastern and southern Yunnan. Most of middle and eastern Sichuan Province belongs to the Sichuan Basin with its occluded terrain. The temperature is higher than other areas of the same latitude area and it experiences rich precipitation. It is also the most prominent rainy area in China. Hydrothermal conditions are better, NPP is higher, the dominant vegetation type in western Sichuan is grass, and the snowy mountains account for over $30 \%$ of the land area. The average NPP here is low. Fig. 5 shows the annual NPP anomalies during the study period. From Fig. 2 and Fig. 5, it can be seen that the spatial distribution of drought is consistent with the distribution of NPP anomalies. It can be seen from the figure that obvious negative NPP anomalies appeared in the entire region from 2005-2006 and 2009-2010, which was significantly lower than the 12-year average. Compared with other years, the drought situation in these two years is even more serious and extensive (Fig. 5). According to 
spatial distribution of drought indices (Fig. 2), this is also fully illustrated. Particularly it is worth noting that in 2010, a large range of NPP negative anomalies occurred throughout the region.

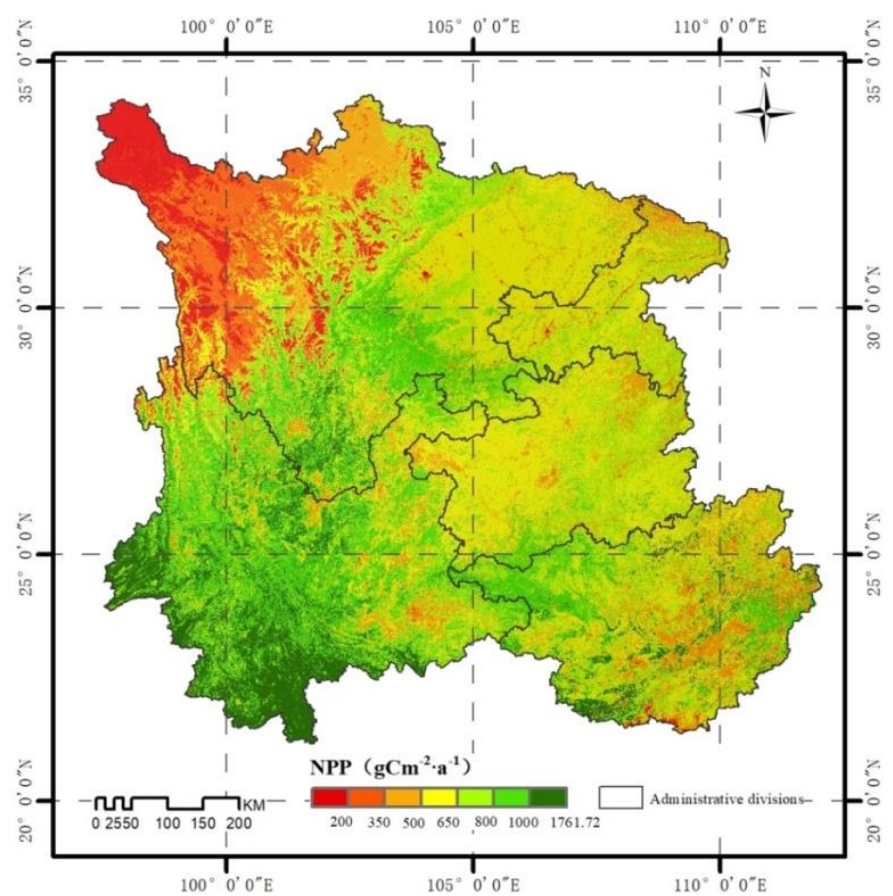

Figure 4. The spatial distribution of mean annual NPP over the 12 years

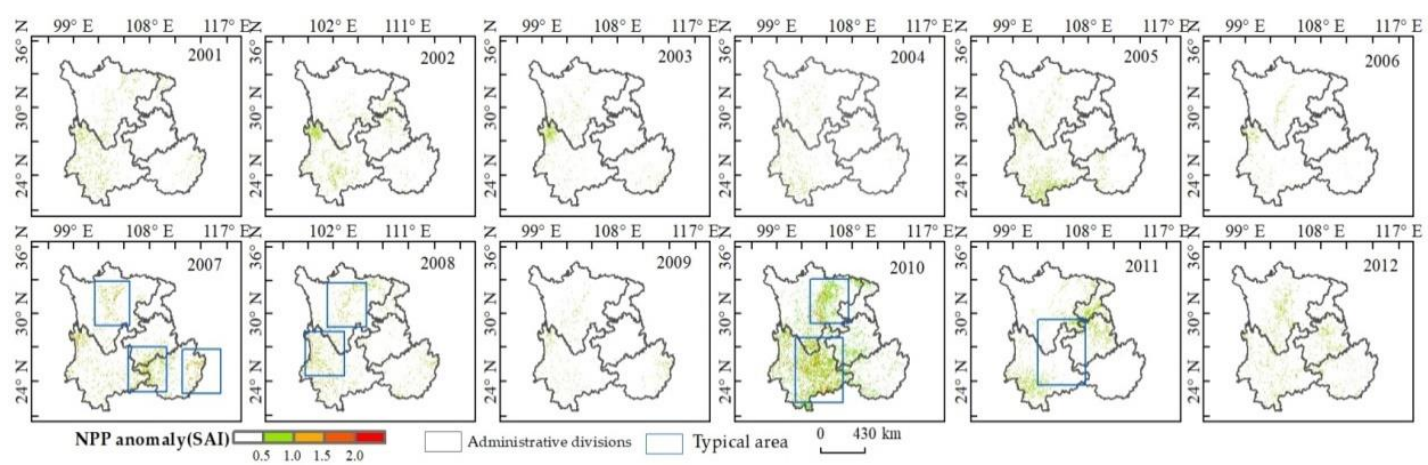

Figure 5. Relative NPP anomalies from the year 2001-2012

Data from other drought years (including 2004, 2006, and 2008) do not indicate a significant reduction in NPP compared with NPP data for 2009 and 2010, which can be explained by the effect level of drought on vegetation productivity. Compared with those in 2005 and 2010, during 2005-2007 and 2008-2010, the percentage of areas that suffered from drought was relatively low, this explains the cause of the NPP anomalies over the 12 years. When the arid area reaches its maximum, the abnormality index (SAI) is the most prominent (Fig. 6), which indicated that severe drought has a much greater impact on regional NPP than mild drought. Pei et al. (2013) pointed out that SAI 
reaches the maximum when the drought intensity reached peaks. This also fully demonstrates that the views of this work are consistent with previous studies. In years when the drought index did not detect anomalies (e.g., 2001 and 2012) (Fig. 6), the NPP anomalies were mainly caused by floods and other reasons.

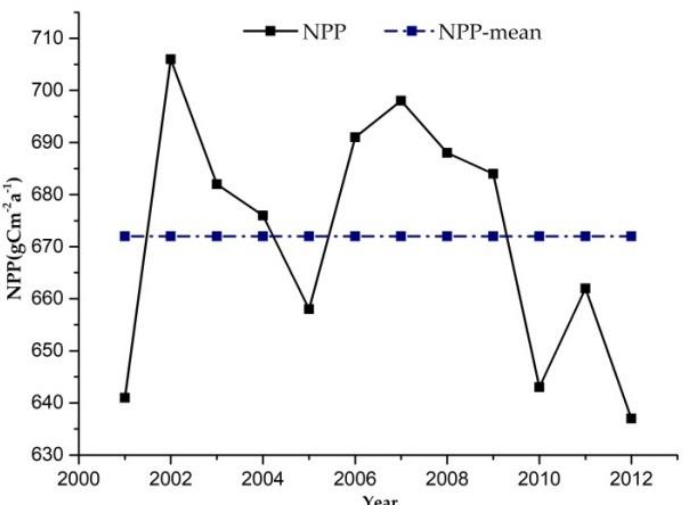

(a)

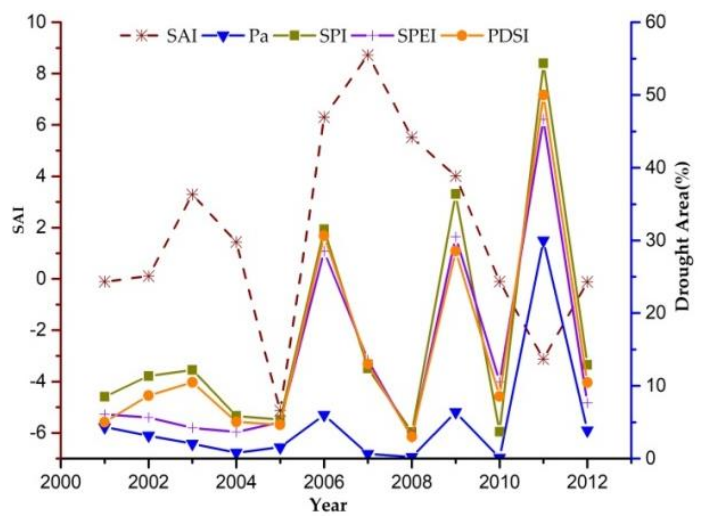

(b)

Figure 6. NPP, SAI and drought area of indices from the year 2001-2012 (a) NPP; (b) SAI and drought area of indices

\section{Monthly variations of Drought impact on vegetation productivity}

To further analyze the impact of drought on vegetation productivity, we calculated the average monthly vegetation productivity (GPP) and analyzed the impact of drought indices on GPP by different vegetation types during typical drought event (Fig. 7 and Fig. 8). In the study period, $92.3 \%$ of the area was hit by severe drought (mild drought), drought mainly occurred in winter and early spring. The drought in 2009 can be traced back to parts of 2008, which is illustrated by the decrease in river water volume in some regions in 2008. The decrease of GPP in 2009 began in October and lasted for four months. Monthly mean GPP $\left(322.55 \mathrm{~g} \mathrm{C} \mathrm{m}^{-2}\right)$ reduction continues for a long time, and monthly mean precipitation $93.53 \mathrm{~mm}$, mean temperature $15.8^{\circ} \mathrm{C}$. We calculated the average GPP under drought conditions ( $\mathrm{Pa}<-0.5$, SPI $<-0.5$, SPEI $<-0.5$, PDSI $<-1.0)$ and analyzed the impact of drought indices on GPP production by different vegetation types. The results indicate that drought indices caused reduction in GPP with the order of: PDSI < SPEI < Pa < SPI. From October 2009 to January 2010, the GPP decline from evergreen forest was the greatest $\left(150 \mathrm{~g} \mathrm{C} \mathrm{m}^{-2}\right)$, followed by shrubland $\left(92 \mathrm{~g} \mathrm{C} \mathrm{m}^{-2}\right)$ and deciduous forest (103 $\mathrm{g} \mathrm{C} \mathrm{m}^{-2}$ ). Since January 2010, drought conditions have eased, vegetation productivity has gradually recovered, and monthly GPP shows a slow rise. In addition, drought has a lagging impact on the productivity of vegetation and GPP is often reflected in the following months. As can be seen from the figure, shrub recovery is the fastest. It can be seen that the changes in the cropland GPP was consistent with the 12-year mean and the decrease was small, which was mainly attributed to human irrigation and other measures. In 2010, the level of drought has eased, and studies show that measures will help alleviate the effects of drought on crops, but they will not prevent the reduction of vegetation. This is also confirmed by the previous research in which the valuation of crop GPP is low. 


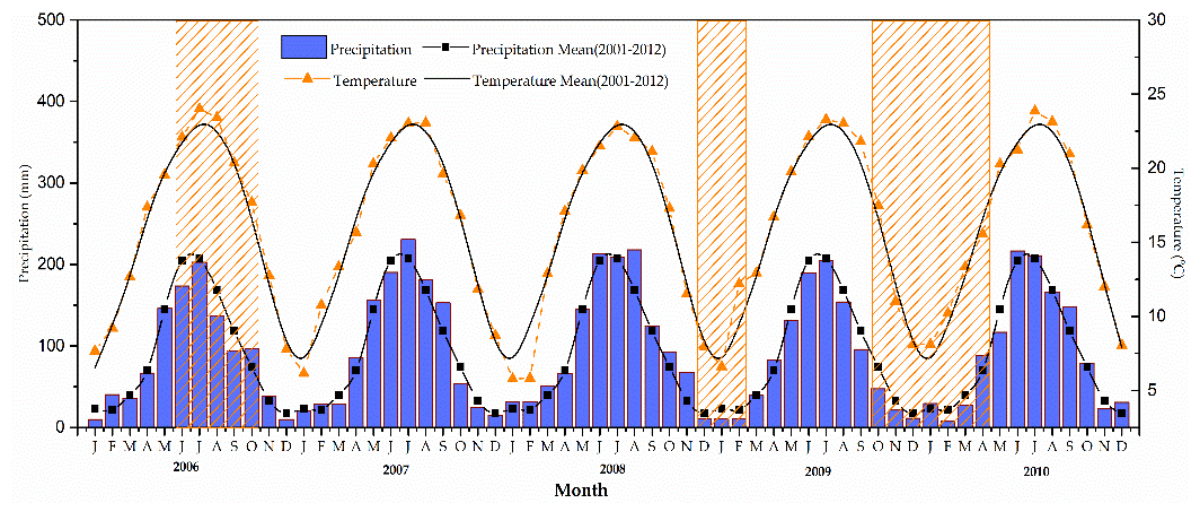

(a)

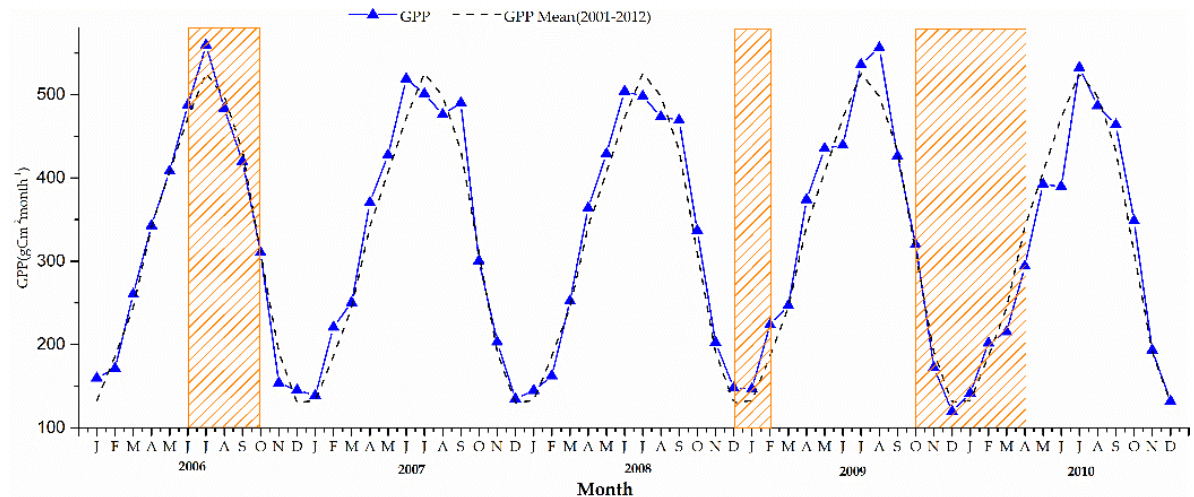

(b)

Figure 7. Monthly GPP, temperature, and precipitation averaged in the SWC over drought period, the orange box denotes the drought period experiencing GPP reduction
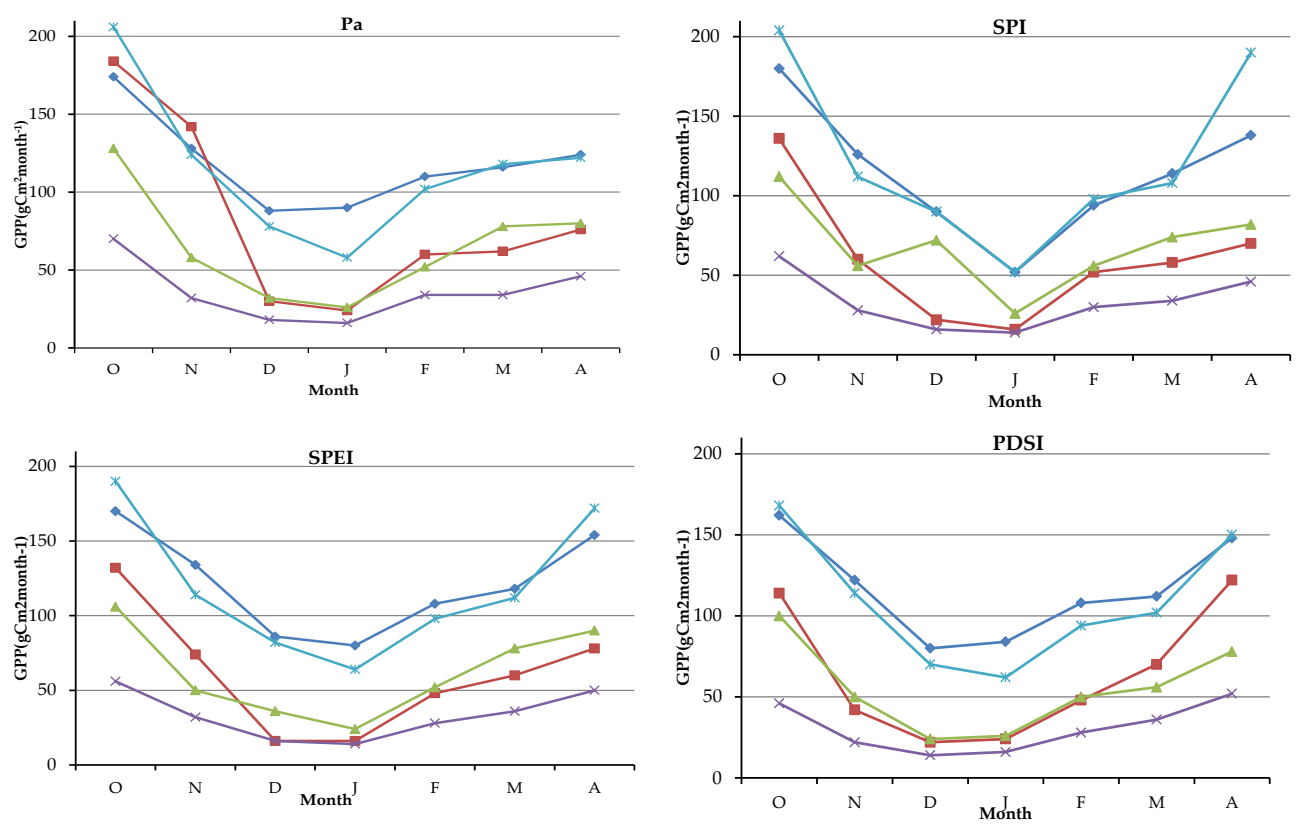

$\rightarrow$ Evergreen forests $\rightarrow$-Deciduous forests $\rightarrow$ Shrublands $\rightarrow$ Croplands $\rightarrow$ Grasslands

Figure 8. Monthly GPP variations of typical vegetation under drought condition during drought period (from October 2009 to April 2010) in SWC

APPLIED ECOLOGY AND ENVIRONMENTAL RESEARCH 17(1):85-105.

http://www.aloki.hu • ISSN 15891623 (Print) • ISSN 17850037 (Online)

DOI: http://dx.doi.org/10.15666/aeer/1701_085105

(c) 2019, ALÖKI Kft., Budapest, Hungary 


$$
-100-
$$

\section{The response of different drought monitor patterns to vegetation productivity}

To understand the relation between vegetation productivity and drought index within monthly scale under each of levels of drought conditions in different monitor patterns. The different indices were compared to GPP during a drought year (2009-2010).

Both SPI and SPEI were found to significantly correlate with monthly GPP under mild drought and extreme drought, with correlation coefficients of 0.745 and 0.752 , respectively (Table 4). In details, Pa reflects the degree of abnormal rainfall, which shows it fails to make a timely response to drought, and overestimate drought levels. The SPI are stable, which could eliminate the temporal and spatial precipitation differences, and it is sensitive to changes in mild drought. SPI is more relevant to drought and it reflects the different regions and periods of drought well. However, the calculation of SPI only incorporates precipitation data. The other crucial factors (e.g. evapotranspiration and temperature) that can affect the frequency of drought are not included. The process of carbon sinks is complicated as the drought continues to develop. The relation between SPI and GPP is not obvious.

Table 4. The fitting results between mean monthly GPP and drought indices at different levels

\begin{tabular}{c|c|c|c}
\hline Drought grade & Fitting equation & Determination coefficient $\mathbf{R}^{\mathbf{2}}$ & Drought index \\
\hline Mild drought & $\mathrm{y}=0.237 \mathrm{x}-38.52$ & 0.745 & SPI \\
Moderate drought & $\mathrm{y}=0.342 \mathrm{x}-61.35$ & 0.673 & SPEI \\
Severe drought & $\mathrm{y}=0.381 \mathrm{x}+34.63$ & 0.638 & PDSI \\
Extreme drought & $\mathrm{y}=0.565 \mathrm{x}-45.58$ & 0.752 & SPEI \\
\hline
\end{tabular}

PDSI is sensitive to GPP in severe droughts and effectively reflects the conditions of water deficit of vegetation. The same pattern was also detected in the correlation between the SPEI and GPP. PDSI and SPEI are more responsive to GPP as the drought continues to develop. It is sure that significant influences of the demand of atmospheric evaporation for vegetation on productivity should be noted. Additionally, the correlations between monthly GPP and drought indices clearly showed that the SPEI and PDSI were most capable of monitoring the vegetation drought conditions in the karst region. The results of this work will provide academic reference for drought ecological risk assessment in the southwestern mountainous areas in China.

\section{Discussion}

Drought may affect the production and living of local residents at all levels. There is a contiguous karst area and the most vulnerable ecological ecosystem in Southwestern China, especially on the particular topography and hydrogeological structure. In this work, we analyze vegetation productivity response in different patterns of drought indicators in karst regions in order to reveal the process and extent of drought disasters, and understand the impacts of extreme weather events. We looked at the relationships between vegetation productivity variability and drought indices, and used multiple linear regression analysis to assess the responses to the drought.

Using different patterns of drought indicators, we identified the main impact factors of spatial and temporal patterns of vegetation productivity change. Monthly variations 
of drought impact on vegetation productivity indicated that monthly mean GPP reduction continues for a long time, drought has a lagging impact on the vegetation productivity and GPP is often reflected in the following months. This is because the response of vegetation to changes in environmental factors, such as precipitation, temperature, and soil moisture, is a gradual process. In general, spring precipitation and temperature variability seem to be the most significant factors controlling vegetation productivity. Spring drought has the greatest impact on vegetation growth.

In this work, forest management practices such as harvest and thinning were not considered. Forest regrowth after harvest could greatly influence the responses of forest to drought conditions, as these forests have higher productivity. Thereby demanding more water and possibly resulting in water shortage. Therefore, our results might somewhat underestimate drought impacts on vegetation productivity (NPP and GPP). Drought is one of the complex natural hazards, affected by many factors. Climate changes, mainly the precipitation changes and air temperature, play the dominant role. However, other factors such as land use, and $\mathrm{CO}_{2}$ concentration were not considered to change with time in this study, which could also result in some uncertainties.

Although the vegetation cover in SWC is high, the karst topography is significant and the rock desertification is serious. Restoration of rocky-desertified karst ecosystems is a hot issue in maintaining the sustainability of environments, economy and society in southwestern China. And the correlation between drought indices and vegetation productivity were analyzed, the nonlinear correlations are not considered.

In addition, there are certain uncertainties between MODIS vegetation productivity products and the measured value, which cannot ensure that the simulated value exactly matches the actual situation. These situations can also lead to uncertainty in the analysis. This work provides an example of extreme climate impacts on karst ecosystems and has important implications for global ecology research. The utilization of water resources would be improved by applying ecological restoration technology to effectively prevent soil moisture infiltration in karst areas over the drought season.

The four drought indices belong to different patterns. Pa and SPI indices, which mainly considering the impact of precipitation; PDSI index, which is an indicator of soil moisture fluctuations, in contrast to $\mathrm{Pa}$ and SPI indices that are based solely on precipitation, PDSI uses both precipitation and temperature as inputs and was correlated significantly with observed soil moisture data. SPEI, considering precipitation and evapotranspiration, and retaining the sensitivity of SPI and PDSI to drought events, reflect the intensity, duration of drought and changes in different time scales. These three patterns for monitoring drought are widely used in recent years. Using different drought patterns, we identified the main drivers of these spatial and temporal patterns of vegetation productivity change, and these results indicated a close relationship between vegetation and drought events. This is consistent with previous studies that drought responses in productivity across sites, and the results highlight the importance of vegetation recovery.

\section{Conclusions}

In this study, we investigated assessments to compare the strengths of different drought indices including Pa, SPI, SPEI, and PDSI in Southwest China. We also analyzed vegetation productivity (annual NPP and monthly GPP). In terms of drought intensity and extent, characteristics were detected in the comparative performances of 
Pa, SPI, SPEI and PDSI. Pa showed consistency in the distribution of drought regions, SPI showed a stronger adaptability and better reflected the temporal and spatial variation. SPEI characterized the effect of temperature and surface evapotranspiration, mainly for moderate and severe drought with the small scope of extreme drought. PDSI is a good indicator of soil moisture fluctuation. The spatial distribution of drought is consistent with the distribution of NPP anomaly, and NPP changes of different vegetation types have different characteristics. The level of NPP is directly proportional to the severity of drought. Large reductions in GPP $\left(66.5 \mathrm{~g} \mathrm{C} \mathrm{m}^{-2}\right)$ were found during both $2009(14.7 \%)$ and $2010(8.4 \%)$ in SWC. The insufficiency of precipitation led to the decrease of NPP from January to April in 2005, and the higher temperature, lower precipitation in 2008-2009 resulted in serious drought. Thus the most severe drought was observed with the largest reduction GPP in 2010. Locations with sparse vegetation have lower productivity. In the region, the GPP of forests, woodlands, and shrub lands exhibited more reductions than that of farmland, which we attribute to irrigation and other measures used by humans. Drought indices caused reduction in GPP with the order of: PDSI < SPEI < Pa < SPI. Our results also suggested relation between vegetation productivity and drought index within monthly scale under each of levels of drought conditions in different monitor patterns, with large differences in the influence of drought conditions on different drought levels. SPEI and PDSI are most capable of monitoring the vegetation drought conditions. Our findings suggested that multi-indices in drought monitoring are needed in order to acquire robust conclusions. The karst area in SWC depend heavily on the very little ecosystem services, especially farming at low elevation, which seem to be the most vulnerable and could collapse due to successive drought events. Further work in this fragile area should focus on improving drought and climate observations and the overall understanding of the expected climate change impact on these fragile and fairly isolated ecosystems in rocky-desertified karst area.

Acknowledgments. This research was funded by the National Key Research and Development Program of China (grant number 2016YFC0803000, 2017YFB0504100), Major Project of High Resolution Earth Observation System (Civil Part) (00-Y30B15-9001-14/16-1) and Youth Innovation Promotion Association of CAS (2015129).

Author Contributions. Z.Y., W.S., W.F. and Q.Y. assisted with the study design and the interpretation of the results; Z.R. designed and wrote the paper.

Conflicts of Interest. The authors declare that they have no conflicts of interest.

\section{REFERENCES}

[1] Angelidis, P., Maris, F., Kotsovinos, N., Hrissanthou, V. (2012): Computation of drought index SPI with alternative distribution function. - Water Resources Management 26: 2453-2473.

[2] Boczon, A., Kowalska, A., Dudzinska, M., Wrobel, M. (2016): Drought in Polish Forests in 2015. - Polish Journal of Environmental Studies 25: 1857-1862.

[3] Carbone, G. J., Lu, J. Y., Brunetti, M. (2018): Estimating uncertainty associated with the standardized precipitation index. - International Journal of Climatology 38(4): 607.

[4] Chang, C. T., Wang, H. C., Huang, C. Y. (2018): Assessment of MODIS-derived indices (2001-2013) to drought across Taiwan's forests. - International Journal of Biometeorol 62: 809-822. 


$$
\text { - } 103 \text { - }
$$

[5] Chen, G. S., Tian, H. Q., Zhang, C., Liu, M. L., Ren, W., Zhu, W. Q., Chappelka, A. H., Prior, S. A., Lockaby, G. B. (2012): Drought in the Southern United States over the 20th century: variability and its impacts on terrestrial ecosystem productivity and carbon storage. - Climatic Change 114: 379-397.

[6] Dai, A. (2011): Drought under global warming: a review. - Wiley Interdisciplinary Reviews Climate Change 2: 45.

[7] Dai, A., Trenberth, K. E., Qian, T. (1965): A global dataset of palmer drought severity index for 1870-2002: relationship with soil moisture and effects of surface warming. Journal of Hydrometeorology 5: 1117-11130.

[8] Dewes, C. F., Rangwala, I., Barsugli, J. J., Hobbins, M. T., Kumar, S. (2017): Drought risk assessment under climate change is sensitive to methodological choices for the estimation of evaporative demand. - PLOS ONE 12(3): 174-196.

[9] El-Vilaly, M. A. S., Didan, K., Marsh, S. E., van Leeuwen, W. J. D., Crimmins, M. A., Munoz, A. B. (2017): Vegetation productivity responses to drought on tribal lands in the four corners region of the Southwest USA. - Frontiers of Earth Science 12: 37-51.

[10] Foley, J. C. (1957): Droughts in Australia: Review of Records from Earnest Years of Settlement to 1955. - Australian Bureau of Meteorology, Bulletin No 43: 128.

[11] Ghali, M., Nejla, B. A. (2017): Digital technologies and farm productivity: an example from livestock farms. - EFITA CONGRESS, Montpellier, France.

[12] Graw, V., Ghazaryan, G., Dall, K., Delgado Gómez, A., Abdel-Hamid, A., Jordaan, A., Piroska, R., Post, J., Szarzynski, J., Walz, Y., Dubovyk, O. (2017): Drought Dynamics and Vegetation Productivity in Different Land Management Systems of Eastern Cape, South Africa-A Remote Sensing Perspective. - Sustainability 9: 1728-1740.

[13] He, D., Wang, J., Pan, Z. H., Dai, T., Wang, E. L., Zhang, J. P. (2016): Changes in wheat potential productivity and drought severity in Southwest China. - Theoretical and applied climatology 130: 477.

[14] He, D., Wang, J., Dai, T., Feng, L., Zhang, J., Pan, X., Pan, Z. (2014): Impact of climate change on maize potential productivity and the potential productivity gap in Southwest China. - Journal of Meteorological Research 28: 1155-1167.

[15] Heddinghaus, T. R., Sabol, P. (1991): A review of the Palmer Drought Severity Index and where do we go from here. - Proc. 7th Conf. on Applied Climatology.

[16] Huang, G., Zhang, L. F., Wang, Q. L., Guan, J. P. (2012): Precipitation forecasting experiments based on the products of ensemble forecast by using downscaling method. Journal of the Meteorological Sciences 32: 508-514.

[17] Huang, L., He, B., Chen, A., Wang, H., Liu, J., Lü, A., Chen, Z. (2016): Drought dominates the interannual variability in global terrestrial net primary production by controlling semi-arid ecosystems. - Scientific Reports 6: 24639.

[18] Hutchinson, M. F., Xu, T. (2004): Anusplin Version 4.4, Anuclim Version 6.1. - Fenner School of Environment and Society, Australian National University: Canberra, Australia.

[19] Jiao, C. C., Yu, G. R., Zhan, X. Y., Zhu, X. J., Chen, Z. (2014): Sptial pattern and regional characteristics of global forest ecosystem net primary productivity. - Quaternary Sciences 34: 699-709.

[20] Judi, D. R., Rakowski, C. L., Waichler, S. R., Feng, Y., Wigmosta, M. S. (2018): Integrated Modeling Approach for the Development of Climate-Informed, Actionable Information. Water 10(6): 775.

[21] Koudahe, K., Kayode, A. J., Samson, A. O., Adebola, A. A., Djaman, K. (2017): Trend Analysis in Standardized Precipitation Index and Standardized Anomaly Index in the Context of Climate Change in Southern Togo. - Atmospheric and Climate Sciences 7(4): 401-423.

[22] Leinenkugel, P., Kuenzer, C., Dech, S. (2013): Comparison and Enhancement of MODIS Cloud Mask Products for Southeast Asia. - International Journal of Remote Sensing 34: 2730-2748. 
[23] Li, Q. F., Yang, G. J. (2017): Temporal Distribution Characteristics of Alpine Precipitation and Their Vertical Differentiation: A Case Study from the Upper Shule River. - Water 9: 284-296.

[24] McKee, T. B., Doesken, N. J., Kleist, J. (1993): The relationship of drought frequency and duration to time scales. - Proceedings of the 8th Conference on Applied Climatology, Boston, MA. Am. - Meteorol. Soc. 17(22): 179-183.

[25] McKee, T. B., Doesken, N. J., Kleist, J. (1995): Drought monitoring with multiple time scales. - Ninth Conference on Applied Climatology, American Meteorological Society, Boston, MA: 15-20.

[26] Mika, J., Horvath, S. Z., Makra, L., Dunkel, Z. (2005): The Palmer Drought Severity Index (PDSI) as an Indicator of Soil Moisture. - Physics and Chemistry of the Earth 30: 223-230.

[27] Neumann, M., Moreno, A., Thurnher, C., Mues, V., Härkönen, S., Mura, M., Bouriaud, O., Lang, M., Cardellini, G., Thivolle-Cazat, A., Bronisz, K., Merganic, J., Alberdi, I., Astrup, R., Mohren, F., Zhao, M., Hasenauer, H. (2016): Creating a Regional MODIS Satellite-Driven Net Primary Production Dataset for European Forests. - Remote Sensing 8: 554-572.

[28] Palmer, W. C. (1965): Meteorological Drought. - Washington, DC: US Department of Commerce, Weather Bureau No. 45.

[29] Pei, F., Li, X., Liu, X., Lao, C. (2013): Assessing the Impacts of Droughts on Net Primary Productivity in China. - Journal of Environmental Management 114: 362-371.

[30] Piao, S., Fang, J., He, J. (2006): Variations in vegetation net primary production in the Qinghai-Xizang Plateau, China, from 1982 to 1999. - Climatic Change 74: 253-267.

[31] Potopová, V., Štěpánek, P., Možný, M., Türkott, L., Soukup, J. (2015): Performance of the standardised precipitation evapotranspiration index at various lags for agricultural drought risk assessment in the Czech Republic. - Agric. For. Meteorol. 202: 26-38.

[32] Propastin, P., Ibrom, A., Knohi, A., Erasmi, S. (2012): Effects of Canopy Photosynthesis Saturation on the Estimation of Gross Primary Productivity from MODIS Data in a Tropical Forest. - Remote Sensing of Environment 121: 252-260.

[33] Ran, Y. H., Li, X., Lu, L. (2009): China Land Cover Classification at $1 \mathrm{~km}$ Spatial Resolution Based on a Multi-source Data Fusion Approach. - Advances in earth science 24: 192.

[34] Skagen, S. K., Augustine, D. J., Derner, J. D. (2018): Semi-arid grassland bird responses to patch-burn grazing and drought. - The Journal of Wildlife Management 82: 445-456.

[35] Tang, B., Maimaitiming, A. (2012): Research on temporal and spatial distribution characteristics of natural disasters in Tarim Basin during 1949-1990. - Journal of Arid Land Resources and Environment 26: 124.

[36] Vicente-Serrano, S. M., Beguer, A. S., López-Moreno, J. I. (2009): A multiscalar drought index sensitive to global warming: the standardized precipitation evapotranspiration index. - J Climate 23(7): 1696-1718.

[37] Wang, D., Zhang, B., An, M. L., Zhang, T. F., Ji, D. M., Ren, P. G. (2014): Temporal and Spatial Distributions of Drought in Southwest China over the Past 53 years Based on Standardized Precipitation Evapotranspiration Index. - Journal of natural resources 29: 1003-1016.

[38] Wang, M. T., Wang, X., Huang, W. H., Zhang, Y. F., Ma, J. (2012): Temporal and spatial distribution of seasonal drought in Southwest of China based on relative moisture index. - Transactions of the Chinese Society of Agricultural Engineering (Transactions of the CSAE) 28: 85-92.

[39] Yang, Q., Li, Z. Y. (1994): Analysis on the drought index in arid and semi-arid regions. Journal of Catastrophology 9(2): 12-16.

[40] Yao, N., Li, Y., Lei, T., Peng, L. (2018): Drought evolution, severity and trends in mainland China over 1961-2013. - Science of the Total Environment 616: 73. 
[41] Yu, L., Wang, J., Gong, P. (2013): Improving 30 meter global land cover map FROMGLC with time series MODIS and auxiliary datasets: A segmentation based approach.International Journal of Remote Sensing 34: 5851-5867.

[42] Yu, M. X., Li, Q. F., Hayes, M. J., Svoboda, M. D., Heim, R. R. (2014): Are droughts becoming more frequent or severe in China based on the standardized precipitation evapotranspiration index: 1951-2010?. - International Journal of Climatol 34(3): 545558.

[43] Zhang, B. H., Zhang, L., Guo, H. D., Patrick, L., Zhou, Y., Li, L., Shen, Q. (2014): Drought impact on vegetation productivity in the Lower Mekong Basin. - International Journal of Remote Sensing 35: 2835-2856.

[44] Zhang, L., Xiao, J. F., Li, J., Wang, K., Lei, L. P., Guo, H. D. (2012): The 2010 spring drought reduced primary productivity in southwestern China. - Environmental Research Letters 7: 45.

[45] Zhang, Y., Yu, Q., Jiang, J. I. E., Tang, Y. (2008): Calibration of Terra/MODIS gross primary production over an irrigated cropland on the North China Plain and an alpine meadow on the Tibetan Plateau. - Global Change Biology 14: 757-767.

[46] Zhao, M., Running, S. W. (2010): Drought-induced reduction in global terrestrial net primary production from 2000 through 2009. - Science 329(5994): 940-943.

[47] Zhao, A., Zhang, A., Cao, S., Liu, X., Liu, J., Cheng, D. (2018): Responses of vegetation productivity to multi-scale drought in Loess Plateau, China. - Catena 163: 165-171. 